\title{
Corrosion Inhibitive Action and Adsorption Behaviour of Justicia Secunda Leaves Extract as an Eco-Friendly Inhibitor for Aluminium in Acidic Media
}

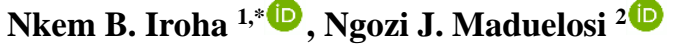 \\ 1 Electrochemistry and Material Science Unit, Department of Chemistry, Federal University Otuoke, Nigeria \\ 2 Department of Chemistry, Rivers State University, Port Harcourt, Nigeria \\ * Correspondence: irohanb@fuotuoke.edu.ng.com; nkemib@yahoo.com (N.B.I.);
}

Scopus Author ID 57219613634

Received: 2.01.2021; Revised: 27.01.2021; Accepted: 30.01.2021; Published: 7.02.2021

\begin{abstract}
The extract of Justicia secunda (JS) leaves was investigated as an eco-friendly corrosion inhibitor of aluminum in $0.5 \mathrm{M} \mathrm{HCl}$ using weight loss, electrochemical impedance spectroscopy (EIS), potentiodynamic polarization (PDP), and scanning electron microscopy (SEM) techniques. The inhibitor concentrations used ranged from 50 to $250 \mathrm{ppm}$ at 30,40 , and $50^{\circ} \mathrm{C}$. Results show that Justicia secunda acts as a good inhibitor for aluminum. Its efficiency increased with increasing inhibitor concentration but decreased with increasing temperature. Maximum inhibition efficiency as high as $94.3 \%$ was found at $30^{\circ} \mathrm{C}$ for $250 \mathrm{ppm}$ of the inhibitor with the weight loss technique. Tafel polarization results show that the extract acts as a mixed-type inhibitor. The Nyquist plots indicated decreasing double-layer capacitance and increasing charge transfer resistance on increasing JS concentration. The inhibition action occurred through the physical adsorption of the extract on the aluminum surface. The adsorption process was found to follow Langmuir adsorption isotherm. The formation of a protective film on the metal surface was confirmed by scanning electron microscopy.
\end{abstract}

Keywords: Justicia Secunda; eco-friendly; Tafel polarization; corrosion inhibition; aluminium.

(C) 2021 by the authors. This article is an open-access article distributed under the terms and conditions of the Creative Commons Attribution (CC BY) license (https://creativecommons.org/licenses/by/4.0/).

\section{Introduction}

Several applications of aluminum and its alloys have resulted in researches due to its electrochemical behavior and corrosion resistance in a wide variety of media, including investigation of the properties of the surface oxide film formed naturally or by iodization. However, the corrosion of aluminum always takes place in aqueous acidic conditions. Acid solutions are often used in industries for cleaning, descaling, and pickling of metallic structures, processes which are usually accompanied by considerable dissolution of the metal [1-3]. Also, excessive corrosion attack is known to occur on metals deployed in service in aggressive environments. The use of inhibitors during acid pickling is one of the most practical methods for protecting metals against corrosion in acidic media. The addition of inhibitors effectively secures the metal against an acid attack.

The applicability of organic compounds as corrosion inhibitors for metals in acidic media has been recognized for a long time [4-6]. The existing data show that most organic inhibitors act by adsorption on the metal surface. The adsorption of inhibitors occurs through heteroatoms such as nitrogen, oxygen, phosphorus, and sulfur, triple bonds, or aromatic rings. These compounds which are adsorbed on the metallic surface block the active corrosion sites. 
However, most of these compounds are expensive and toxic to the environment [7]. Green corrosion inhibitors are safe, biodegradable, and environmentally friendly. Natural products as corrosion inhibitors for metallic protection can be traced to the last half of the nineteenth century. Most researchers recently started studying the application of extracts of some common plant as corrosion inhibitors [8-11]. These extracts contain different hydroxy organic compounds, e.g., tannins, pectin, flavonoids, anthraquinones, steroids, saponins, and coumarins, in addition to other nitrogen-containing compounds.

The plant Justicia secunda (JS) is a creeping perennial herb that belongs to the Acanthaceae family. The phytochemical analysis of JS leaves revealed the presence of flavonoids, saponins, tannins, alkaloids, and steroids. Saponins, flavonoids, and tannins were found to be present in higher concentrations [12]. The presence of flavonoids and tannins in many plant extract accounts for their ability to retarding the corrosion rate of some metals/alloys in various aggressive environments $[13,14]$. The present paper reports on the corrosion inhibition of extracts from JS leaves on aluminum in $0.5 \mathrm{M} \mathrm{HCl}$ solutions using weight loss, electrochemical impedance spectroscopy, and polarization techniques. Also, scanning electron microscopy (SEM) was performed to investigate the surface morphology variations by introducing the inhibitor.

\section{Materials and Methods}

\subsection{Material preparation.}

Aluminium alloy sheets with weight percentage composition as follows: $\mathrm{Al}$ (98.473), $\mathrm{Si}$ (0.456), Fe (0.760), Cu (0.069), Mn (0.116), Mg (0.020), Zn (0.053), Ti (0.016), Cr (0.005), $\mathrm{Ni}(0.004), \mathrm{V}(0.007), \mathrm{Pb}(0.021)$ were used in this study. Each $\mathrm{Al}$ sheet of $0.1 \mathrm{~cm}$ thickness was mechanically pressed-cut into coupons of dimensions $2 \mathrm{~cm} \mathrm{x} 4 \mathrm{~cm}$ for all experiments. For weight loss measurement, a uniform hole of diameter $2 \mathrm{~mm}$ was drilled to facilitate suspension of the test solution' coupon. For the electrochemical study, the aluminum specimens were covered in epoxy resin with a surface area of $1 \mathrm{~cm}^{2}$ exposed to the test solution. Before the tests, the coupons were abraded using different grades of emery papers (\#400 - 1000), degreased in absolute ethanol, dried in acetone, weighed, and stored in a moisture-free desiccator prior to use. The $0.5 \mathrm{M} \mathrm{HCl}$ solution, prepared from $\mathrm{BDH}$ grade $\mathrm{HCl}$ was employed as the study's corrodent.

\subsection{Inhibitor preparation.}

Justicia secunda leaves obtained from a garden in Otuoke, Bayelsa State, Nigeria, and authenticated in the University of Port Harcourt herbarium were dried and crushed to powder. To prepare the plant extract stock solutions, weighed amounts of the powder were boiled in a $0.5 \mathrm{M} \mathrm{HCl}$ solution for 3 hours. The resulting solution was cooled, then filtered and stored. From the stock solution, inhibitor test solutions were prepared in the concentration range of 50 - 250 ppm using excess acid as solvent.

\subsection{Weight loss measurement.}

Tests were conducted under total immersion conditions maintained at 30,40 , and $50^{\circ} \mathrm{C}$. The pre-cleaned and weighed coupons were suspended in beakers containing the test solutions using a glass rod and hook. All tests were made in aerated solutions. To determine weight loss 
with respect to time, the coupons were retrieved from test solutions at 2 hours intervals progressively for 10 hours, scrubbed with bristle brush under running water, dried in acetone, and re-weighed. The weight loss was taken to be the difference between the weight of the coupons at a given time and its initial weight. From the weight loss data, the corrosion rates $(C R)$ were calculated from the following equation:

$$
\mathrm{CR}=\frac{\Delta \mathrm{W}}{\mathrm{At}}
$$

where $\Delta \mathrm{W}$ is weight loss in $\mathrm{mg}, \mathrm{A}$ is the specimen surface area in $\mathrm{cm}^{2}$ and $\mathrm{t}$ is the end time of each experiment in hours. From the corrosion rate, the surface coverage $(\theta)$ as a result of adsorption of inhibitor molecules, and inhibition efficiencies of the molecules (IEWL \%) were determined using equations (2) and (3), respectively.

$$
\begin{aligned}
& \theta=\frac{\mathrm{CR}_{\text {bla }}-\mathrm{CR}_{\text {inh }}}{\mathrm{CR}_{\text {bla }}} \\
& \mathrm{IE}_{\mathrm{WL}} \%=\frac{\mathrm{CR}_{\text {bla }}-\mathrm{CR}_{\text {inh }}}{\mathrm{CR}_{\text {bla }}} \times \frac{100}{1}
\end{aligned}
$$

where $\mathrm{CR}_{\text {bla }}$ and $\mathrm{CR}_{\text {inh }}$ are the corrosion rates in the absence and presence of the inhibitor, respectively.

\subsection{Electrochemical measurements.}

Electrochemical measurements were performed using a VoltaLab 40 PGZ301 potentiostat in a standard electrochemical three-electrode cell; with a platinum counter electrode, a saturated calomel reference electrode (SCE), and the aluminum as working electrode (WE). All measurements were carried out at $30^{\circ} \mathrm{C}$ using $100 \mathrm{ml}$ of electrolyte $(0.5 \mathrm{M}$ $\mathrm{HCl}$ ) in a stationary condition. The open-circuit potential (OCP) steady-state values were obtained at the end of 30 min of immersion before each measurement. The EIS measurement was performed over a frequency range of $100 \mathrm{kHz}-0.1 \mathrm{~Hz}$ with an AC signal amplitude perturbation of $10 \mathrm{mV}$ peak-to-peak. The charge transfer resistance $\left(R_{c t}\right)$ values were computed from the Nyquist plots. The following equation calculated the percentage inhibition efficiency:

$$
\mathrm{IE}_{\mathrm{EIS}} \%=\frac{\mathrm{R}_{\mathrm{ct}(\mathrm{inh})}-\mathrm{R}_{\mathrm{ct}(\mathrm{bla})}}{\mathrm{R}_{\mathrm{ct}(\mathrm{inh})}} \times 100
$$

Where Rct(blank) and Rct(inh) are the charge transfer resistances without and in the JS inhibitor presence.

Potentiodynamic polarization measurements were carried out from $+250 \mathrm{mV}$ to -250 $\mathrm{mV}$ vs. SCE at OCP with a scan rate of $1 \mathrm{mV} \mathrm{s}^{-1}$. The linear Tafel segment of cathodic and anodic curves was extrapolated to the intersection point to obtain corrosion potential ( $\left.\mathrm{E}_{\text {corr }}\right)$ and corrosion current density ( $\mathrm{i}_{\text {corr }}$ ). The inhibiting efficiency (IEPDP\%) value for the PDP method was evaluated from the calculated $i_{\text {corr }}$ values using the relationship:

$$
\mathrm{IE}_{\mathrm{PDP}} \%=\frac{\mathrm{i}_{\text {corr(bla) }}-\mathrm{i}_{\text {corr }(\mathrm{inh})}}{\mathrm{i}_{\mathrm{corr}(\mathrm{bla})}} \times 100
$$

where $\mathrm{i}_{\text {corr(bla) }}$ and $\mathrm{i}_{\text {corr(inh) }}$ are the corrosion current density in the presence and in the absence of inhibitor, respectively.

\subsection{Scanning electron microscopy (SEM).}

FEI QUANTA 200 scanning electron microscope (SEM) was used to ascertain the morphological changes occurring on the aluminum surface due to the corrosion process before and after the inhibitors' addition. The specimens with a freshly pre-treated surface described in section 2.1 were immersed in $0.5 \mathrm{M} \mathrm{HCl}$ in the absence and presence of $250 \mathrm{ppm}$ of the 
studied JS for $6 \mathrm{~h}$ at $30^{\circ} \mathrm{C}$. The specimens were then removed from the test solutions, washed with bi-distilled water and acetone, dried, and used for SEM analysis

\section{Results and Discussion}

\subsection{Weight loss measurement.}

Table 1 presents the effects of JS leaves extract on aluminum's corrosion behavior in a $0.5 \mathrm{M} \mathrm{HCl}$ solution. The results show that corrosion rates were reduced in the presence of JS leaves extract compared to the blank acid solution. It was also observed that the corrosion rate of aluminum in the presence of the inhibitor decreases with an increase in concentration, indicating that the protection ability of the inhibitor is concentration-dependent. From Figure 1 , the inhibition efficiency increases with an increase in the concentration of JS leaves extract. This trend results from the increased adsorption of organic compounds present in the inhibitor onto the aluminum surface [15].

Table 1. Corrosion rate and inhibition efficiency ( $\mathrm{IE}_{\mathrm{WL}} \%$ ) of $\mathrm{JS}$ extract on aluminum corrosion in $0.5 \mathrm{M} \mathrm{HCl}$ at

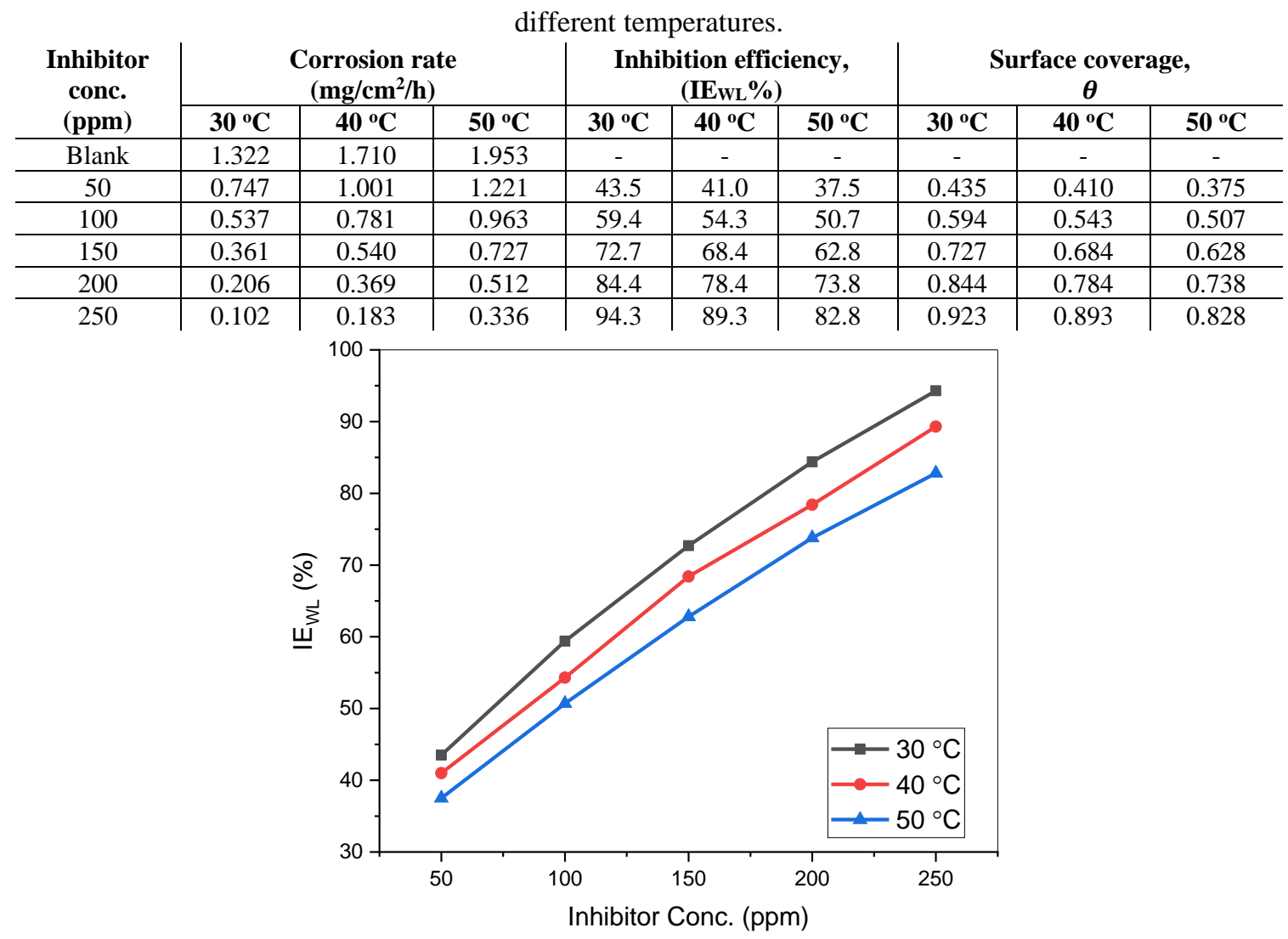

Figure 1. Variation of inhibition efficiency ( $\mathrm{IE}_{\mathrm{WL}} \%$ ) with inhibitor concentration for aluminum in $0.5 \mathrm{M} \mathrm{HCl}$ containing JS leaves extract at various temperatures.

\subsection{Potentiodynamic polarization (PDP) measurement.}

Potentiodynamic polarization studies were performed to gain insights into the aluminum dissolution mechanism at the anode and the evolution of hydrogen at the cathode in the absence and presence of different concentrations of JS. Figure 2 shows anodic and cathodic polarization plots recorded on an aluminum electrode in $0.5 \mathrm{M} \mathrm{HCl}$ without different JS inhibitor concentrations. The electrochemical parameters obtained from these plots are presented in Table 2 . The corrosion current density (icorr) decreased and inhibition efficiency 
(IEPDP\%) increased with an increase in JS concentration, probably due to the adsorption of the inhibitor on the aluminum/acid solution interface, indicating that the inhibitor is effective for aluminum corrosion in $0.5 \mathrm{M} \mathrm{HCl}[16,17]$. It is worthy of note that JS inhibitor's presence shifted both the anodic and cathodic curves to lower values of current densities, which indicates that both the hydrogen evolution and the anodic dissolution of aluminum metal are inhibited. This is typical behavior for a mixed-type corrosion inhibitor. As reported in the literature [18$20]$, if the displacement in $\mathrm{E}_{\text {corr }}$ value is $>85 \mathrm{mV}$, the inhibitor can be seen as a cathodic or anodic type inhibitor; if the displacement of $\mathrm{E}_{\text {corr }}$ value is $<85 \mathrm{mV}$, the inhibitor can be seen as mixed type. In the present study, the maximum displacement in $\mathrm{E}_{\text {corr }}$ was much lower than 85 $\mathrm{mV}$ suggesting that JS extract is a mixed-type inhibitor with a predominance of cathodic inhibition.

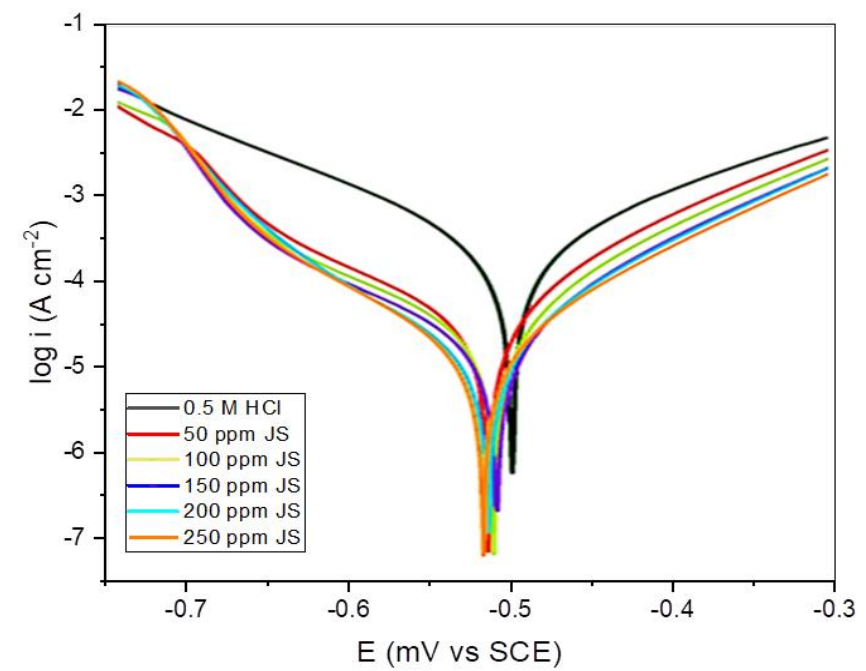

Figure 2. Potentiodynamic polarization curves for corrosion of aluminum in $0.5 \mathrm{M} \mathrm{HCl}$ containing different JS extract concentration at $30^{\circ} \mathrm{C}$.

Table 2. Polarization parameters for corrosion of aluminum in $0.5 \mathrm{M} \mathrm{HCl}$ containing various JS extract

\begin{tabular}{|c|c|c|c|c|c|}
\hline \multicolumn{6}{|c|}{ concentration at $30^{\circ} \mathrm{C}$. } \\
\hline $\begin{array}{c}\text { Concentration } \\
(\mathbf{p p m})\end{array}$ & $\begin{array}{c}\mathbf{E}_{\text {corr }} \\
(\mathbf{m V / S C E})\end{array}$ & $\begin{array}{c}\mathbf{i}_{\text {corr }} \\
\left(\mu \mathbf{A ~ c m}^{-2}\right)\end{array}$ & $\begin{array}{c}\boldsymbol{\beta a}_{\mathrm{a}} \\
\left(\mathbf{m V} \mathbf{d e c}^{-1}\right)\end{array}$ & $\begin{array}{c}\boldsymbol{\beta}_{\mathbf{c}} \\
\left(\mathbf{m V} \mathbf{d e c}^{-1}\right)\end{array}$ & $\begin{array}{c}\text { IE PDP } \\
(\%)\end{array}$ \\
\hline Blank & -497 & 743.9 & 152.5 & 129.7 & - \\
\hline 50 & -521 & 431.7 & 116.4 & 108.3 & 42.0 \\
\hline 100 & -509 & 328.5 & 107.2 & 99.8 & 55.8 \\
\hline 150 & -507 & 198.3 & 96.3 & 90.1 & 72.8 \\
\hline 200 & -512 & 87.3 & 92.7 & 85.2 & 88.3 \\
\hline 250 & -524 & 71.6 & 91.5 & 79.7 & 90.4 \\
\hline
\end{tabular}

\subsection{Electrochemical Impedance Spectroscopy (EIS)}

The electrochemical corrosion behavior of aluminum in $0.5 \mathrm{M} \mathrm{HCl}$ solution in the absence and presence of various concentrations of the JS extract was investigated using EIS at $30^{\circ} \mathrm{C}$. Figure 3 shows the aluminum sample's Nyquist plots in $0.5 \mathrm{M} \mathrm{HCl}$ in the absence and presence of different concentrations of JS extract. The Nyquist plots showed a depressed capacitive loop. Inspection of Figure 3 reveals that the modulus of the Nyquist plots in $0.5 \mathrm{M}$ $\mathrm{HCl}$ solution without the inhibitor was much smaller than that in the presence of JS extract. The fact that impedance diagrams have an approximately semi-circular appearance shows that the charge transfer resistance process controls aluminum corrosion in $0.5 \mathrm{M} \mathrm{HCl}$. The capacitive loop deviation from a complete semi-circle can be referred to as the working electrode surface's heterogeneity and microroughness [21,22]. Nyquist plot's diameter increased on increasing the JS extract concentration, which indicates that the extract 
strengthens the inhibitive film. The electrical equivalent circuit model that describes the present corroding system's metal/electrolyte interface is shown in Figure 4. The equivalent circuit is composed of a solution resistance $\left(R_{s}\right)$, a charge transfer resistance $\left(R_{c t}\right)$, and a constant phase element (CPE) that replaces the capacitive element to obtain a more accurate fit. The impedance $\left(\mathrm{Z}_{\mathrm{CPE}}\right)$ of a CPE can be expressed using the following relations [2,23].

$$
\mathrm{Z}_{\mathrm{CPE}}=\mathrm{Y}_{0}^{-1}(\mathrm{j} \omega)^{-n}
$$

where $\mathrm{Y}_{0}$ is the CPE constant, $\mathrm{j}=(-1)^{1 / 2}, \omega$ is the angular frequency in $\mathrm{rad} \mathrm{s}^{-1}$, and the value of $n$ (the phase shift) ranges between 0 and 1 . When $\mathrm{n}=1$, the CPE becomes equivalent to an ideal capacitor, and when $n=0$, the CPE becomes equivalent to a resistor. The values of doublelayer capacitance $\left(\mathrm{Cdl}_{\mathrm{dl}}\right)$ with and without inhibitors were calculated using the following equation [24,25]:

$$
\mathrm{C}_{\mathrm{dl}}=\mathrm{Y}_{0}\left(\omega_{\max }\right)^{\mathrm{n}-1}
$$

where, $\omega_{\max }$ is the angular frequency at which the imaginary part of impedance has a maximum value. The electrochemical parameters obtained from EIS are summarized in Tables 3. It is apparent from Table 3 that the presence of the extract in the acid medium leads to an increase in $\mathrm{R}_{\mathrm{ct}}$ and reduction of $\mathrm{C}_{\mathrm{dl}}$ values. The decrease in $\mathrm{C}_{\mathrm{dl}}$ values is related to the adsorption of inhibitor molecules on the metal surface. It then leads to a decrease in the local dielectric constant and/or an increase in the thickness of the electrical double layer [26]. The increase in $\mathrm{R}_{\mathrm{ct}}$ values with an increase in the concentration of JS extract indicates an increase in the corrosion inhibition efficiency in an acidic solution observed by an increase in IEEIS\%.

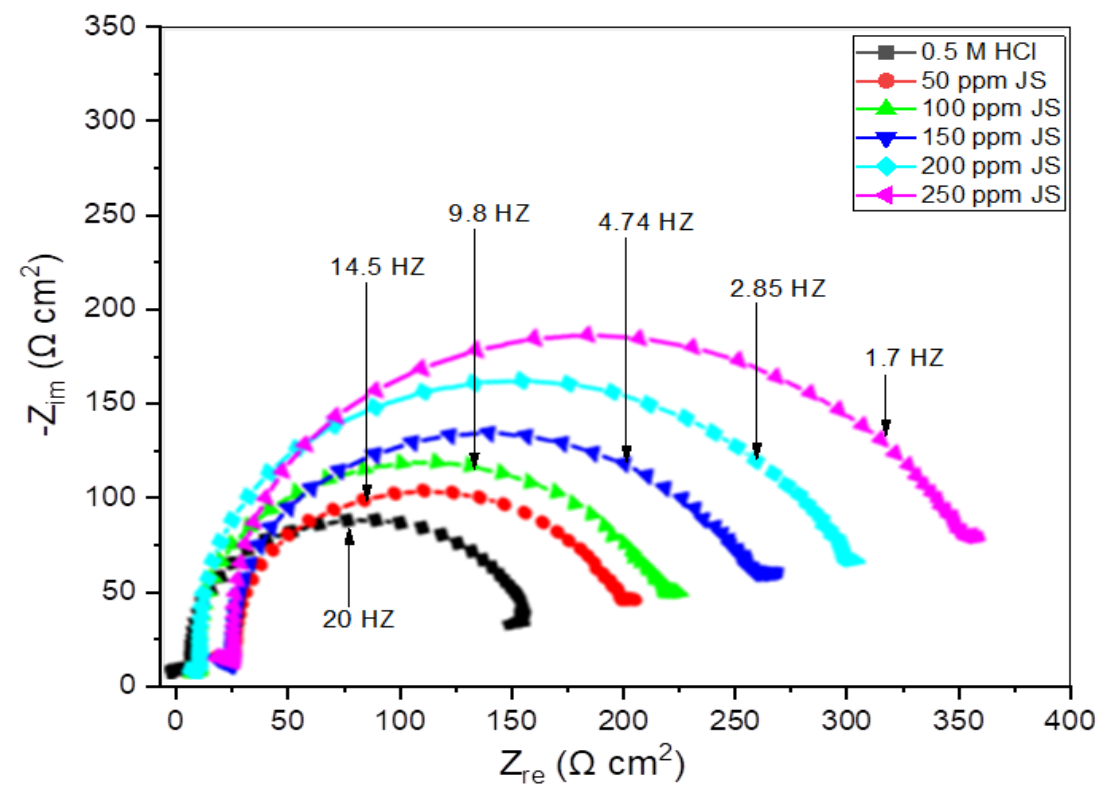

Figure 3. Nyquist plots of aluminum in $0.5 \mathrm{M} \mathrm{HCl}$ without and with various concentrations of JS extract.

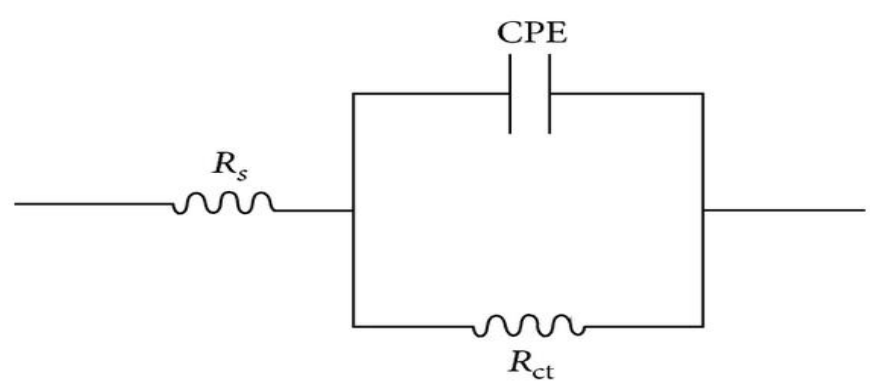

Figure 4. Equivalent circuit model used to fit EIS data. 
Table 3. EIS parameters for the corrosion of aluminum in $0.5 \mathrm{M} \mathrm{HCl}$ at various concentrations of JS extract.

\begin{tabular}{ccccccc}
\hline $\begin{array}{c}\text { Concentration } \\
(\mathbf{p p m})\end{array}$ & $\begin{array}{c}\mathbf{R}_{\mathbf{s}} \\
\left(\boldsymbol{\Omega} \mathbf{~ c m}^{\mathbf{2}}\right)\end{array}$ & $\begin{array}{c}\mathbf{R}_{\mathbf{c t}} \\
\left(\mathbf{\Omega} \mathbf{c m}^{\mathbf{2}}\right)\end{array}$ & $\begin{array}{c}\mathbf{Y}_{\mathbf{o}} \\
\left(\boldsymbol{\mu} \mathbf{\Omega}^{-\mathbf{1}} \mathbf{s}^{\mathbf{n}} \mathbf{c m}^{-\mathbf{2}}\right)\end{array}$ & $\begin{array}{c}\mathbf{C}_{\mathbf{d l}} \\
\left(\boldsymbol{\mu} \mathbf{F} \mathbf{c m}^{-\mathbf{2}}\right)\end{array}$ & $\boldsymbol{n}$ & $\begin{array}{c}\mathbf{I E}_{\mathbf{E I S}} \\
(\mathbf{\%})\end{array}$ \\
\hline Blank & 1.08 & 17.5 & 302.3 & 218.3 & 0.891 & - \\
50 & 1.17 & 30.8 & 259.2 & 153.2 & 0.899 & 43.2 \\
100 & 1.31 & 42.3 & 227.1 & 118.2 & 0.902 & 58.6 \\
150 & 1.58 & 58.7 & 204.2 & 82.1 & 0.915 & 70.2 \\
200 & 1.74 & 91.4 & 186.3 & 57.5 & 0.919 & 80.9 \\
250 & 1.92 & 182.1 & 163.9 & 17.6 & 0.927 & 90.4 \\
\hline
\end{tabular}

\subsection{Effect of temperature.}

The influence of temperature on aluminum's corrosion behavior in $0.5 \mathrm{M} \mathrm{HCl}$ in the absence and presence of JS leaves extract was investigated using the weight loss method at 30 , 40 , and $50{ }^{\circ} \mathrm{C}$. The corrosion rate increases with temperature rise both in the absence and in the presence of the additives. Figure 1 shows that inhibition efficiency increases with the increase in JS leaves extract concentration but decreases with temperature increase. The decrease in inhibition efficiency with an increase in temperature suggests the physical adsorption of JS leaves extract onto the aluminum surface. Also, in examining the effect of temperature on the corrosion inhibition process, the apparent activation energies $\left(E_{a}\right)$ were deduced from the Arrhenius equation [27]:

$$
\log C R=\log A-\frac{E_{a}}{2.303 R T}
$$

where $\mathrm{CR}$ and $\mathrm{T}$ are the corrosion rate and temperature, respectively, A the pre-exponential factor and $\mathrm{R}$ the molar gas constant. The Ea values were calculated from the slope of the Arrhenius plots of $\log$ CR vs. 1/T shown in Figure 5. The calculated $E_{a}$ values are presented in Table 4. The activation energies in the presence of inhibitors may be higher, equal to, or lower than those in the inhibitor's absence. In the present study, it could be seen that with increasing concentration of JS leaves extract, the apparent activation energy increased, which is suggestive of the physical adsorption mechanism of JS on the aluminum surface [28,29]. The increase of activation energies in the presence of inhibitor is attributed to an appreciable decrease in the inhibitor's adsorption process on the Al surface with temperature rise and the corresponding increase in the reaction rate due to greater area of the metal exposed to acid [2]

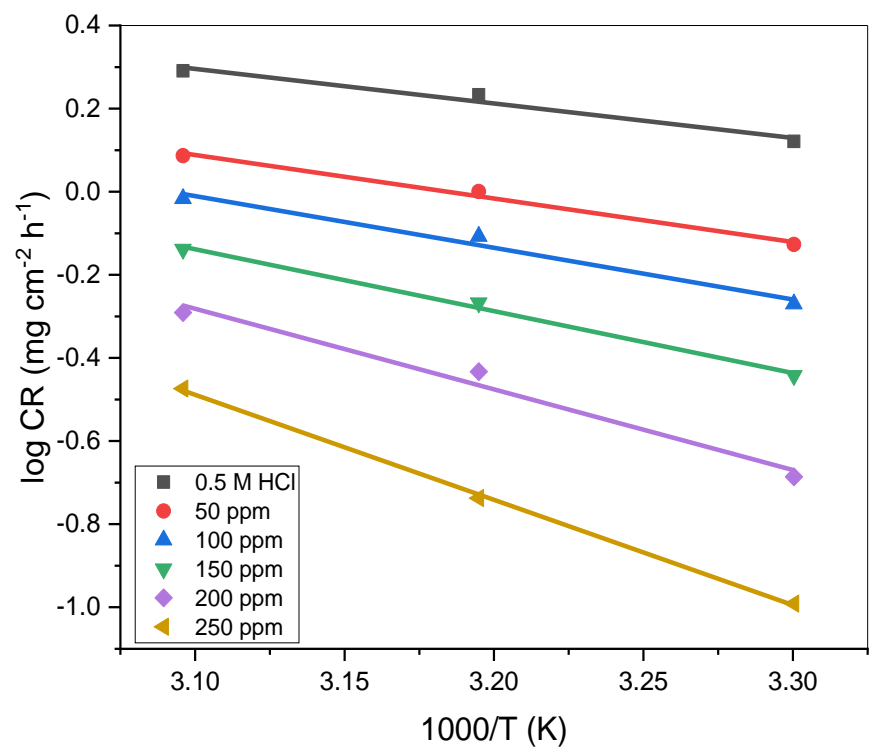

Figure 5. Arrhenius plots of aluminum in $0.5 \mathrm{M} \mathrm{HCl}$ without and with different concentrations of JS leaves extract. 
Table 4. Calculated values of activation energy $\left(E_{a}\right)$ for aluminum dissolution in $0.5 \mathrm{M} \mathrm{HCl}$ in the absence and presence of JS leaves extract.

\begin{tabular}{cc}
\hline Inhibitor concentration $(\mathbf{p p m})$ & Activation energy $(\mathbf{K J} \mathbf{J} \mathbf{m o l})$ \\
\hline Blank & 24.19 \\
10 & 25.22 \\
20 & 28.03 \\
30 & 33.76 \\
40 & 37.11 \\
50 & 38.93 \\
\hline
\end{tabular}

\subsection{Adsorption considerations.}

The effectiveness of organic compounds as corrosion inhibitors can be ascribed to the molecules' adsorption through their polar functions on the metal surface. Adsorption isotherm values are important to explain the mechanism of corrosion inhibition of organoelectrochemical reactions. The frequently used adsorption isotherm include Langmuir, Frumkin, Temkin, Flory-Huggins, among others. Langmuir isotherm was tested for its suitability to the experimental data. Langmuir isotherm is given by the expression:

$$
\frac{\mathrm{C}_{\mathrm{inh}}}{\theta}=\frac{1}{\mathrm{~K}_{\mathrm{ads}}}+\mathrm{C}
$$

where $\theta$ is the degree of surface coverage, $\mathrm{C}_{\mathrm{inh}}$ is the inhibitor concentration, $\mathrm{K}_{\mathrm{ads}}$ is the equilibrium constant of the adsorption process. The plots of $\mathrm{C}_{\mathrm{inh}} / \theta$ against $\mathrm{C}_{\text {inh }}$ are shown in Figure 6. The intercept of the plots is equated to $1 / \mathrm{K}_{\mathrm{ads}}$, from which $\mathrm{K}_{\mathrm{ads}}$ values were calculated. Linear plots were obtained with a good correlation coefficient $\left(\mathrm{R}^{2}\right)$, which suggests that the inhibitor's adsorption follows Langmuir adsorption isotherm. Since it obeys Langmuir adsorption isotherm, it implies monolayer adsorption of inhibitor. The inhibitor's adsorption on the metal surface leads to a high degree of surface coverage and shows better inhibitive property [30]. The equilibrium constant of adsorption $K_{a d s}$ decreases with an increase in temperature (Table 5), indicating that the interactions between the adsorbed molecules and the metal surface are weakened. Consequently, the adsorbed molecules could become easily removable. Such data explains the decrease in the inhibition efficiency with increasing temperature [31].

The equilibrium constant of adsorption of JS leaves extract on aluminum alloy's surface is related to the standard free energy of adsorption $\Delta \mathrm{G}_{\text {ads }}$ by Equation 9 .

$$
\Delta \mathrm{G}_{\text {ads }}^{0}=-2.303 \mathrm{RT} \log \left(55.5 \mathrm{~K}_{\mathrm{ads}}\right)
$$

where $R$ is the molar gas constant, $T$ is the absolute temperature, and 55.5 is the water concentration in solution expressed in $\mathrm{mol} \mathrm{L}^{-1}$. The calculated values of $\mathrm{K}_{\text {ads }}$ and $\Delta \mathrm{G}_{\text {ads }}^{0}$ are presented in Table 5. The negative values of $\Delta \mathrm{G}_{\text {ads }}^{0}$ suggest that the adsorption of JS leaves extract onto the aluminum alloy surface is spontaneous. The values of $\Delta \mathrm{G}_{\text {ads }}^{0}$ obtained indicate that adsorption of JS leaves extract occurs via a physical adsorption mechanism. Generally, the values of $\Delta \mathrm{G}_{\text {ads }}^{0}$ less negative or equal to $-20 \mathrm{kJmol}^{-1}$ (as obtained in this study) are consistent with electrostatic interaction between the charged metals and charged molecules, signifying physical adsorption, while values are more negative than $-40 \mathrm{kJmol}^{-1}$ signify chemical adsorption [32,33].

Table 5. Calculated thermodynamic parameters from Langmuir adsorption isotherm.

\begin{tabular}{c|c|c|c} 
Temperature $\left({ }^{\circ} \mathbf{C}\right)$ & $\mathbf{K}_{\text {ads }}$ & $\boldsymbol{\Delta} \boldsymbol{G}_{\text {ads }}(\mathbf{k J} / \mathbf{m o l})$ & $\mathbf{R}^{\mathbf{2}}$ \\
\hline 30 & 0.62 & -8.92 & 0.9871 \\
\hline 40 & 0.51 & -8.70 & 0.9715 \\
\hline 50 & 0.45 & -8.64 & 0.9740
\end{tabular}




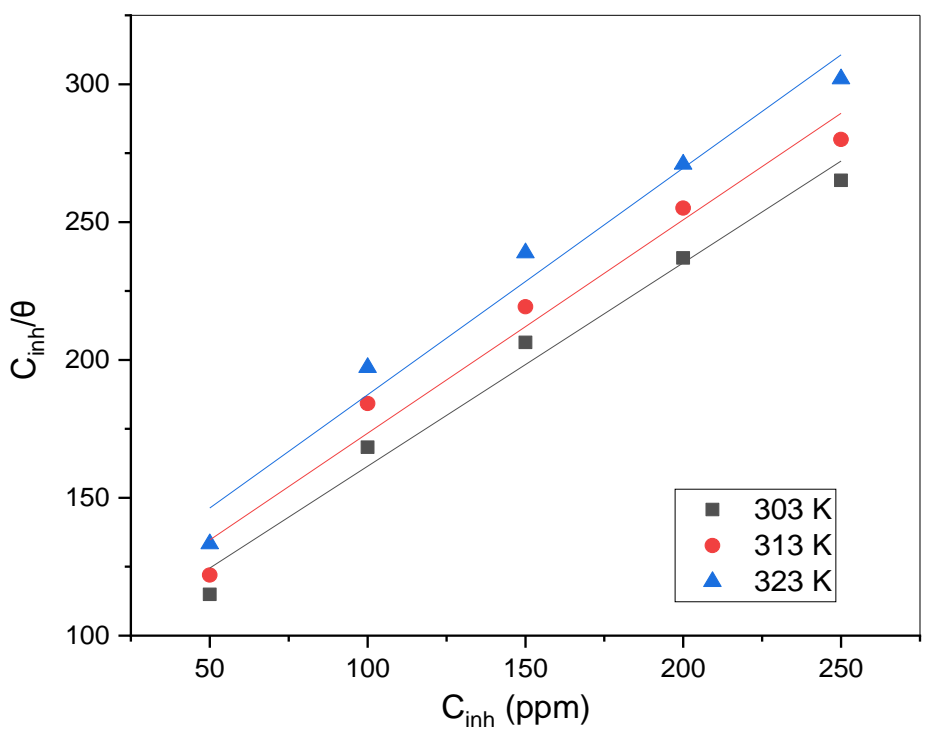

Figure 6. Langmuir Isotherm for the adsorption of JS leaves extract on aluminum in $0.5 \mathrm{M} \mathrm{HCl}$ at different temperatures.

\subsection{Scanning electron microscopy (SEM).}

Surface examination of the aluminum surface corroded in the absence and presence of optimum concentration $(250 \mathrm{ppm}$ ) of JS extract was performed using SEM. The images obtained are shown in Figure 7. The aluminum specimen's surface retrieved from the $0.5 \mathrm{M} \mathrm{HCl}$ solution without inhibitor (Fig. 7a) shows a rough surface with pronounced cavities and isolated furrows due to severe corrosion damage. However, the aluminum specimen's surface retrieved from the acid solution containing 250 ppm of JS extract (Figure 7b) shows a comparatively smoother morphology. The added JS extract covered almost all the cavities present on the surface, forming a barrier between the metal and the acid medium, preventing further corrosion.
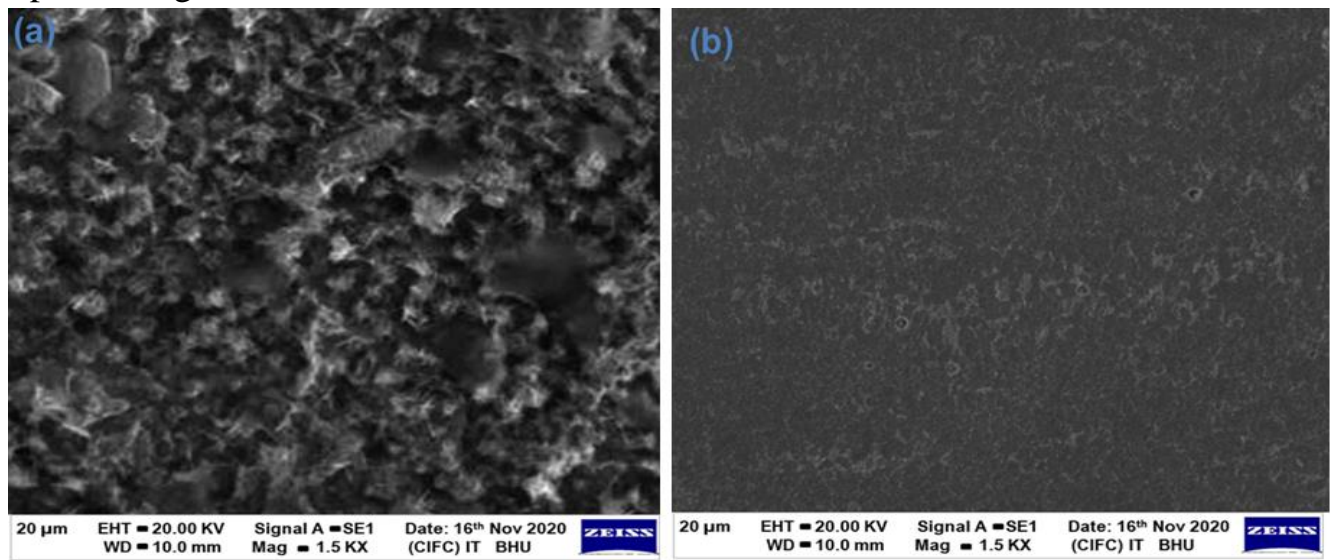

Figure 7. Scanning electron micrographs of aluminum surface immersed for $6 \mathrm{~h}$ in (a) absence; (b) presence of $250 \mathrm{ppm}$ JS leaves extract.

\section{Conclusions}

Justicia secunda (JS) leaves extract was an efficient inhibitor for aluminum in the 0.5 $\mathrm{M} \mathrm{HCl}$ solution. The corrosion rate of the aluminum in $0.5 \mathrm{M} \mathrm{HCl}$ is a function of the inhibitor's concentration. This rate decreased as the concentration of the inhibitor is increased. This inhibitor's percentage inhibition efficiency decreased as the temperature increases, indicating that physical adsorption was the predominant inhibition mechanism. Polarization studies reveal that the adsorbed JS species inhibited the corrosion process through a mixed-inhibition mechanism, affecting both the anodic dissolution reaction and cathodic hydrogen evolution 
reaction. EIS measurements showed that in the presence of the inhibitor, the corrosion current density decreased. Surface morphology studies by SEM confirmed the adsorption of JS. Justicia secunda leaves extract is an eco-friendly corrosion inhibitor for aluminum in the 0.5 $\mathrm{M} \mathrm{HCl}$ solution to replace toxic and expensive corrosion inhibitors.

\section{Funding}

This research received no external funding.

\section{Acknowledgments}

NBI would like to acknowledge the financial support received from Federal University Otuoke, Bayelsa, Nigeria. NJM acknowledges Rivers State University, Port Harcourt, Nigeria, for providing technical support.

\section{Conflicts of Interest}

The authors declare no conflict of interest.

\section{References}

1. Ennouri, A.; Lamiri, A.; Essahli, M. Corrosion Inhibition of Aluminium in Acidic Media by Different Extracts of Trigonellafoenum-graecum L Seeds. Portugaliae Electrochimica Acta 2017, 35, 279-295, http://dx.doi.org/10.4152/pea.201705279.

2. Maduelosi, N.J.; Iroha, N.B. Insight into the Adsorption and Inhibitive Effect of Spironolactone Drug on C38 Carbon Steel Corrosion in Hydrochloric Acid Environment. Journal of Bio- and Tribo-Corrosion 2020, 7, 6, https://doi.org/10.1007/s40735-020-00441-z.

3. Olasunkanmi, L.O.; Ebenso, E.E. Experimental and computational studies onpropanone derivatives of quinoxalin-6-yl-4,5-dihydropyrazole as inhibitors of mild steel corrosion in hydrochloric acid. Journal of Colloid and Interface Science 2020, 561, 104-116, https://doi.org/10.1016/j.jcis.2019.11.097.

4. El Kacimi, Y.; Azaroual, M.A.; Touir, R.; Galai, M.; Alaoui, K.; Sfaira, M.; Ebn Touhami, M.; Kaya, S. Corrosion inhibition studies for mild steel in $5.0 \mathrm{M} \mathrm{HCl}$ by substituted phenyltetrazole. Euro-Mediterranean Journal for Environmental Integration 2017, 2, 1, https://doi.org/10.1007/s41207-016-0011-8.

5. Iroha, N.; Oguzie, E.; Onuoha, G.; Onuchukwu, A. Inhibition of Mild Steel Corrosion in Acidic Solution by derivatives of Diphenyl Glyoxal. 16th International Corrosion Congress, Beijing, China. 2005, 126-131.

6. Verma, C.; Olasunkanmi, L.O.; Ebenso, E.E.; Quraishi, M.A.; Obot, I.B. Adsorption Behavior of Glucosamine-Based, Pyrimidine-Fused Heterocycles as Green Corrosion Inhibitors for Mild Steel: Experimental and Theoretical Studies. The Journal of Physical Chemistry C 2016, 120, 11598-11611, https://doi.org/10.1021/acs.jpcc.6b04429.

7. Iroha, N.B.; Akaranta, O. Experimental and surface morphological study of corrosion inhibition of N80 carbon steel in $\mathrm{HCl}$ stimulated acidizing solution using gum exudate from Terminalia Mentaly. SN Applied Sciences 2020, 2, 1514, https://doi.org/10.1007/s42452-020-03296-8.

8. Dehghani, A.; Bahlakeh, G.; Ramezanzadeh, B. A detailed electrochemical/theoretical exploration of the aqueous Chinese gooseberry fruit shell extract as a green and cheap corrosion inhibitor for mild steel in acidic solution. Journal of Molecular Liquids 2019, 282, 366-384, https://doi.org/10.1016/j.molliq.2019.03.011.

9. Chen, S.; Zhu, B.; Liang, X. Corrosion Inhibition Performance of Coconut Leaf Extract as a Green Corrosion Inhibitor for X65 Steel in Hydrochloric Acid Solution. Int. J. Electrochem. Sci 2020, 15, 1-15, https://doi.org/10.20964/2020.01.39.

10. Idouhli, R.; Koumya, Y.; Khadiri, M.; Aityoub, A.; Abouelfida, A.; Benyaich, A. Inhibitory effect of Senecio anteuphorbium as green corrosion inhibitor for S300 steel. International Journal of Industrial Chemistry 2019, 10, 133-143, https://doi.org/10.1007/s40090-019-0179-2.

11. Iroha, N.; Maduelosi, N. Stem extract of Dissotis theifolia (Melastomataceae) as a green corrosion inhibitor for $\mathrm{N} 80$ steel in $1 \mathrm{M} \mathrm{HCl}$ solution. IOSR Journal of Applied Chemistry 2020, 13, 30-38, http://dx.doi.org/10.9790/5736-1303013038. 
12. Ejovi, O.; Hamilton-Amachree, A. Comparative Study on the Phytochemical and In Vitro Antioxidant Properties of Methanolic Leaf Extract of Justicia Secunda Vahl. Nigerian Journal of Science and Environment. 2017, 15, 111-117.

13. Udensi, S.C.; Ekpe, O.E.; Nnanna, L.A. Newbouldia laevis Leaves Extract as Tenable Eco-Friendly Corrosion Inhibitor for Aluminium Alloy AA7075-T7351 in $1 \mathrm{M} \mathrm{HCl} \mathrm{Corrosive} \mathrm{Environment:} \mathrm{Gravimetric,}$ Electrochemical and Thermodynamic Studies. Chemistry Africa 2020, 3, 303-316, https://doi.org/10.1007/s42250-020-00131-w.

14. James, A.O.; Iroha, N.B. An investigation on the inhibitory action of modified almond extract on the corrosion of Q235 mild steel in acid environment. IOSR Journal of Applied Chemistry 2019, 12, 01-10.

15. Akinbulumo, O.A.; Odejobi, O.J.; Odekanle, E.L. Thermodynamics and adsorption study of the corrosion inhibition of mild steel by Euphorbia heterophylla L. extract in $1.5 \mathrm{M} \mathrm{HCl}$. Results in Materials 2020, 5 , 100074, https://doi.org/10.1016/j.rinma.2020.100074.

16. Mahross, M.H.; Efil, K.; El-Nasr, T.A.S.; Abbas, O.A. Synthesis, Characterization and Corrosion Inhibition of N'-Phenylbenzohydrazide Derivative Metal Complexes: Experimental and Quantum Chemical Studies. Zeitschrift für Physikalische Chemie 2019, 233, 949-972, https://doi.org/10.1515/zpch-2018-1211.

17. Iroha, N.B.; Nnanna, L.A. Electrochemical and Adsorption Study of the anticorrosion behavior of Cefepime on Pipeline steel surface in acidic Solution. Journal of Materials and Environmental Sciences 2019, 10, 898908.

18. Raviprabha, K.; Ramesh, S.B. 5-(3-Pryridyl)-4H-1,2,4-triazole-3-thiol as Potential Corrosion Inhibitor for AA6061 Aluminium Alloy in 0.1 M Hydrochloric Acid Solution. Surface Engineering and Applied Electrochemistry 2019, 55, 723-733, https://doi.org/10.3103/S1068375519060103.

19. Iroha, N.B.; Nnanna, L.A. Leucas Martinicensis as an Inhibitor of Carbon Steel Corrosion in Acidic Medium. International Journal of Research 2019, 7, 19-26.

20. Iroha, N.B.; Maduelosi, N.J. Pipeline steel protection in oil well acidizing fluids using expired pharmaceutical agent. Chemistry International 2020, 6, 267-276, https://doi.org/10.5281/zenodo.3735669.

21. Sliem, M.H.; Afifi, M.; Bahgat Radwan, A.; Fayyad, E.M.; Shibl, M.F.; Heakal, F.E.-T.; Abdullah, A.M. AEO7 Surfactant as an Eco-Friendly Corrosion Inhibitor for Carbon Steel in $\mathrm{HCl}$ solution. Scientific Reports 2019, 9, 2319, https://doi.org/10.1038/s41598-018-37254-7.

22. Iroha, N.B.; Madueke, N.A.; Mkpenie, V.; Ogunyemi, B.T.; Nnanna, L.A.; Singh, S.; Akpan, E.D.; Ebenso, E.E. Experimental, adsorption, quantum chemical and molecular dynamics simulation studies on the corrosion inhibition performance of Vincamine on 55 steel in acidic medium. Journal of Molecular Structure 2021, 1227, 129533, https://doi.org/10.1016/j.molstruc.2020.129533.

23. Verma, C.; Quraishi, M.A.; Singh, A. A thermodynamical, electrochemical, theoretical and surface investigation of diheteroaryl thioethers as effective corrosion inhibitors for mild steel in $1 \mathrm{M} \mathrm{HCl}$. Journal of the Taiwan Institute of Chemical Engineers 2016, 58, 127-140, http://dx.doi.org/10.1016/j.jtice.2015.06.020.

24. Iroha, N.B.; Nnanna, L.A. Tranexamic Acid as Novel Corrosion Inhibitor for X60 Steel in Oil Well Acidizing Fluids: Surface Morphology, Gravimetric and Electrochemical Studies. Progress in Color, Colorants and Coatings 2021, 14, 1-11

25. Kumari, P.D.R.; Nayak, J.; Shetty, A.N. 3-Methyl-4-amino-5-mercapto-1,2,4-triazole as corrosion inhibitor for $6061 \mathrm{Al}$ alloy in $0.5 \mathrm{M}$ sodium hydroxide solution. Journal of Coatings Technology and Research 2011, 8, 685, https://doi.org/10.1007/s11998-011-9341-2.

26. Mobin, M.; Rizvi, M. Polysaccharide from Plantago as a green corrosion inhibitor for carbon steel in $1 \mathrm{M} \mathrm{HCl}$ solution. Carbohydrate Polymers 2017, 160, 172-183, https://doi.org/10.1016/j.carbpol.2016.12.056.

27. Iroha, N.B.; Ukpe, R.A. Investigation of the Inhibition of the Corrosion of carbon steel in Solution of $\mathrm{HCl}$ by Glimepiride. Communication in Physical Sciences 2010, 5.

28. Tong, Z.-Z.; Xue, J.-Q.; Wang, R.-Y.; Huang, J.; Xu, J.-T.; Fan, Z.-Q. Hierarchical self-assembly, photoresponsive phase behavior and variable tensile property of azobenzene-containing ABA triblock copolymers. RSC Advances 2015, 5, 4030-4040, https://doi.org/10.1039/C4RA12844C.

29. Iroha, N.B.; James, A.O.. Adsorption behavior of pharmaceutically active dexketoprofen as sustainable corrosion Inhibitor for API X80 carbon steel in acidic medium. World News of Natural Sciences 2019, 27, 22-37.

30. Chidiebere, M.A.; Oguzie, E.E.; Liu, L.; Li, Y.; Wang, F. Inhibitory Action of Funtumia elastica Extracts on the Corrosion of Q235 Mild Steel in Hydrochloric Acid Medium: Experimental and Theoretical Studies. Journal of Dispersion Science and Technology 2015, 36, 1115-1125, http://dx.doi.org/10.1080/01932691.2014.956114. 
31. Rani, D.P; Selvaraj, S. Inhibitive and adsorption properties of Punica Granatum extract on Brass in acid media. Journal of Phytology 2010, 2, 58-64.

32. Ahmed, S.K.; Ali, W.B.; Khadom, A.A. Synthesis and investigations of heterocyclic compounds as corrosion inhibitors for mild steel in hydrochloric acid. International Journal of Industrial Chemistry 2019, 10, 159173, https://doi.org/10.1007/s40090-019-0181-8.

33. Wang, X.; Yang, H.; Wang, F. An investigation of benzimidazole derivative as corrosion inhibitor for mild steel in different concentration $\mathrm{HCl}$ solutions. Corrosion Science 2011, 53, 113-121, https://doi.org/10.1016/j.corsci.2010.09.029. 